Health, New York City; Physician to the New York Skin and Cancer Hospital, \&c. Vol. I. London and Philadelphia: J. B. Lippincott Company. Pp. 64 and 24 plates. Price 25s. net. - This is the first volume of an atlas of plates of diseases of the skin, some of the parts of which we noticed when they were issued separately in a former edition. The plates are coloured reproductions of photographs and very successfully represent the conditions which they are intended to portray. The present edition contains many new plates and is suitable for those who, without any very great knowledge of dermatology, wish to diagnose a case of disease of the skin. Equally valuable will be found the directions for treatment. The diseases of the skin are dealt with in alphabetical order and the present volume begins with Acne and goes on to Eczema.

Physical Culture Exeroises. By F. W. Strevens.-We have received from Messrs. Charles Jones and Co., printers and stationers, London, the above-mentioned little book of which they are presumably the publishers. Mr. Stevens, if we may judge by his preface, is a teacher of physical movements who seems to have studied his subject from a commonsense point of view. The general hints with which his book commences are quite sensible and he gives a warning against hurrying the physical education of the body which is quite worth notice. Ten exercises illustrated by reproductions of photographs are given in the book, together with instructions how to perform them, and we think that if carried out by an intelligent pupil they would be of value in bringing about a healthy state of physical culture.

Bath as a Fealth Resort. Published by the Corporation of Bath. Pp. 46. Price 1s.-We have received a little handbook bearing the above title which has been issued by the corporation of Bath with the avowed intention of appealing to the public in order that British seekers after health may try Bath instead of going to foreign spas. We need not here repeat what we have already said about Bath as a health resort from the point of view of the medical qualities of the waters. ${ }^{1}$ We may, however, mention that we referred to the fact that the private slaughter-houses should be done away with and that the sanitation of the Mineral Water Hospital was far from perfect. With regard to the former point we are informed that the public abattoir has not been provided but that there are still 28 private slaughter-houses. This is not as it should be, but while London still possesses private slaughter-houses it is not for the capital to cavil at a provincial city. With regard to the sanitation of the Mineral Water Hospital, we are glad to know that our "thoroughly justifiable report," to quote the medical officer of health, had its effect, and that, according to his report for 1901, "it would now be difficult to suggest any improvement in the general sanitary arrangements." For beauty of situation and of architectural design there are few cities with which Bath need fear comparison. I he handbook is carefully written and well illustrated, some of the pictures being in colours. We hope that it will meet with the success which it deserves.

\section{JOURNALS AND MAGAZINES.}

The Practitioner.-The October issue of this journal is devoted to the subject of the diseases of infancy and constitutes a valuable addition to already existent practical directions upon this important matter. The side of the question most affecting the practitioner is broached in a thorough manner, beginning with an article upon the hygiene of the mother before the birth of her child. Then follows a contribution from Dr. M. Handfield-Jones dealing with some points relating to the mother's milk in the early

1 The Lances, Oct. 14th, 1899, p. 1061. weeks of infant life. Dr. George F. Still writes on the use and abuse of patent foods, Dr. W. S. Colman on infantile scurvy, and a "pharmacopœia for infants," by Dr. O. F. F. Grünbaum, is among the other articles in a very useful production.

The Edinburgh Medical Journal.'-The October number of this magazine contains a special article dealing with medical education in the United Kingdom, giving the regulations and requirements of the various examining bodies. The original articles include one by Mr. D. M. Greig on the Surgical Treatment of Empyema in which we may note that the author has no hesitation in washing out the pleural cavity if this seems the most effectual means of ridding it of its purulent contents, and one by Mr. J. Rutherford Morison on Gall-stones. Dr. W. Robertson deals with an outbreak of plague which occurred at Leith and the origin of which was not traced; he notes that the intravenous injection of Yersin's serum was followed by rapid disappearance of the buboes in patients who were already convalescent. As a prophylactic this substance is not infallible, as was shown in the case of a member of the sanitary authority who contracted plague after such inoculation.

the Suottish Medical and Surgical Journal.-This journal devotes some space in its October number to a con. sideration of educational facilities in Scotland. Professor William Stephenson writes of some further obstetric views which need reviewing, dealing in the present paper with some of the early phenomena of labour. Dr. J. W. Ballantyne narrates a case of Malta Fever occurring during Pregnancy and notes that even a high degree of fever does not necessarily produce abortion. A clinical lecture on Percussion of the Apices of the Lungs, by Dr. J. Mackie Whyte, and some remarks on the "Narcosis" Phase of Chloroform Anæsthesia, by Dr. D. C. A. McAllum, complete the original articles in this number.

The Birmingham Medical Revien.-Some selections from Professor R. Saundby's lectures on Medical Ethics delivered in the University of Birmingham form interesting reading in a recent number of this journal, dealing as they do with the subjects of professional secrecy and consultations; they will be continued in subsequent numbers. Dr. Leonard L. B. Williams writes of "Rheumatics" in Relation to Climate, meaning by the term the various forms of arthritis apart from acute rheumatism which are popularly embraced under this term, and concluding that "the climatic factors which are found in association with rhematics are those which interfere primarily with the cutaneous functions." $\mathrm{He}$ attacks the use of woollen materials for underwear and notes incidentally that most people have a tendency to wear too much clothing

\section{触化}

\section{AN AN ESTHETIST'S TABLE.}

THE table here described, which has been most admirably executed by Messrs. Arnold and Sons of London, is a copy in metal and glass with some improvements by myself of a table in wood, at present in use in the Cardiff Infirmary, designed by our ophthalmic surgeon, Mr. F. P. Cresswell, when house surgeon. The frame is made of enamelled iron and the shelves below of plate glass. The top has a small metal shelf above at the back with holes for one pound bottles of chloroform, ether, and A.C.F., a Junker bottle, and a drop bottle. On the top are placed masks, face-pieces syringes, \&c. There are a rim three parts round the top and a double rail in front to prevent small bottles, \&c., from being knocked or shaken off. Around the top there are hooks for Clover bags, gas bags, \&c. Immediately beneath the top is a metal drawer with partitions for gags, tongue forceps, 
hypodermic syringes, strycbnine, brandy, \&c. The glass shelf half-way down the frame, of the same size as the top, is for the kidney dish, towels, \&c. The glass shelf near the

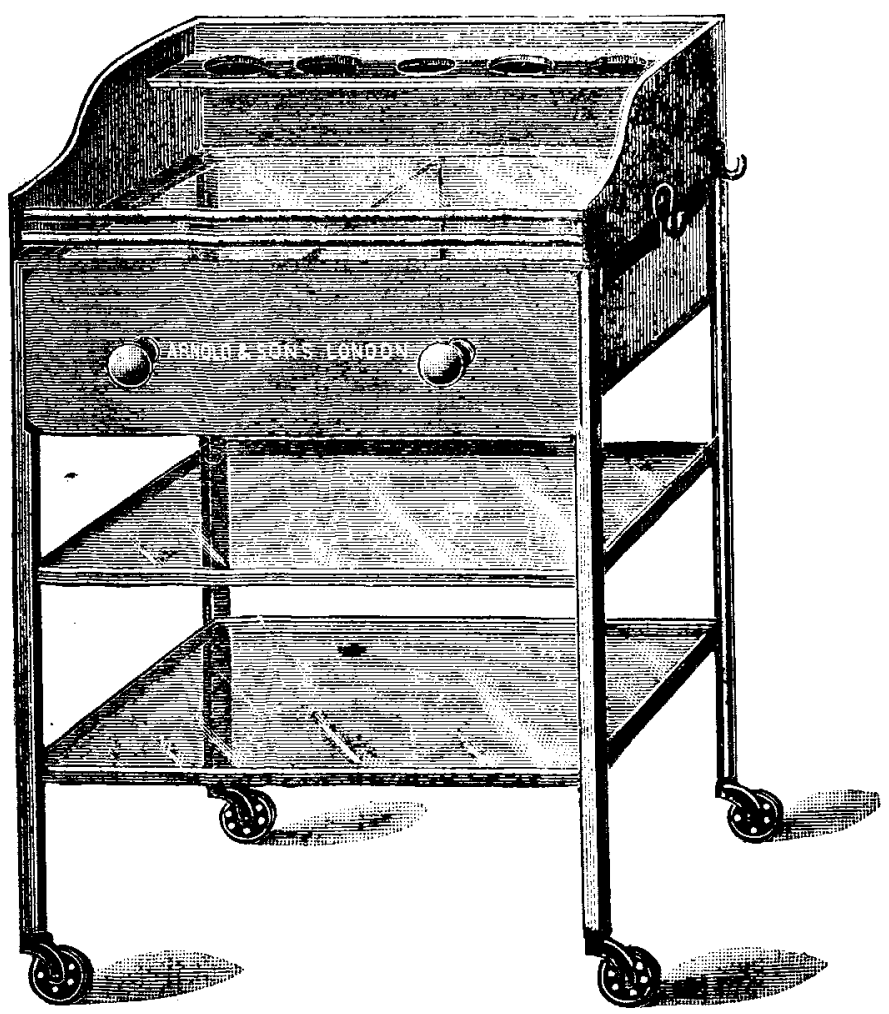

feet, also fitting the frame, is for cylnders of gas and oxygen. 'T he frame is mounted on smoothly working castors and is rigid. li ht, and starle.

F. W. S. Daries, M.R.C.S. Eng., L.R.C.P. Lond., Senior Anæsthetist, Cardiff Infirmary.

ETHYL CHLORIDE IN METAL CYLINDERS.

Messre. B. Kühn and Co., 16, Rood-lane, L.ondon, E.C., have si bmitted to our notice some samples of the tubes of ethyl chloride which they supply. In place of the glass tubes in which the very volatile liquid is usually contained they employ metal cylinders which are much less liable to breakage. Instead of the glass orifice there is a metal "acorn" which is not so readily blocked, and if blocked it can be easily removed for cleaning, or, if necessary, a fresh acorn can be adjusted. Patent automatic headpieces are also supplied, which are more convenient in use than screws. Another advantage of the metal cylinders is that they can be refilled at home. Reservoirs of from 1 to 3 kilogrammes each can be obtained and it is very simple to refill the small cylinders from a reservoir. Thus the price is materially reduced. The metal cylinders are certainly more convenient than those of glass. We consider that the automatic stoppers should be made of rather stouter metal as we found that the one supplied to us was very easily bent.

\section{THE CACHE HOLDFAST ENEMA.}

THIs enema apparatus, which is specially designed for the use of travellers, is packed in a bag exactly resembling the ordinary sfonge bag in every-day use and is therefore less likely to attract attention than if carried in a box or otherwise. A kowl about five and a half inches in diameter for holding the fluid to be injected is also contained in the bag, the indiarubber tube being coiled within it. The end of the indiarubber tuce which carries the valve and dips into the fluid in the bowl is provided with a circular indiarubber sucker similar to the device used for hanging small articles to the inner side of a shop window. As this sucker adheres firmly to the bottom of the bowl the latter is not liable to be overturned and there is no fear of the tube slipping out of the fluid and admitting air to the interior of the apparatus. The bowl is made of white enamelled sheet metal. There is nothing in its appearance to arouse curio:ity and the sucker can either be fixed to it or detached in an instant. The makers are Messrs. W. H. Bailey and Son, 38, Oxford-street, London, W.

\section{Dooking Back.}

\author{
FROM \\ rHE LANCET, SATURDAY, Oct. 20th, 1827.
}

THERE is no portion of the law of England which reflect deeper disgrace on her legislature, than the parliamentary enactments relating to the government of MAD-HOUsEs, and we heartily congratulate the profession and the public on the probability of their speedy repeal. Had those laws been intended to render insanity incurable - to extinguish the liberty of the subject-to furnish instruments wherewith a villain might satiate his revengeful appetite in security-to prevent inquiry into cerebral pathologyto dissipate every rational principle in the treatment-to encourage the cupidity of unprincipled relatives-to place at the disposal of the magistracy a most dangerous and unconstitutional power-to place an equally obnoxious power in the hands of a single medical practitioner-to add incalculably to the horrors of the afflicted-to augment a thousand-fold the exciting causes of the disease-and to render this deplorable malady a valuable article of trade to unprofessional unprincipled, and heartless speculators: they could not have been framed in any manner better calculated to produce such results. In no one respect are those laws founded on sound princip'es-they are radically, systematically defective. It really would seem that they had been adopted by a portion of that description of persons, for whose benefit they were intended. When the blind lead the blind, we know the result.

The evidence contained in the "Report," published by the select committee appointed by Parliament to inquire into the state of the pauper lunatics in the county of Middlesex, has produced an intense feeling of painful interest. Few were prepared to believe that such atrocious practices existed as are spoken of in that document, although we believe more remains behind the curtain than has been exhibited. Enough, however, has been disclosed to satisfy the public that the establishment of a County HospITaL, for the exclusive reception of INSANE PACPER, is imperiously required in the vicinity of the metropolis. The advantages resulting from such an institution, if properly regulated, would be indescribable; and we hope that the magistrates, at their annual meeting, on the 1st of the ensuing month, will show that they are not deaf to the voice of the public and of science, or insensible to the piteous cries of their insane poor.

If such an institntion were founded, and thrown open GRATUITOUSLY, to all medical students (a regulation that ought unquestionably to be adopted,) the entire kingdom would, by that means, participate in its benefits, arising from the increased knowledge of her medical practitioners, in by far the most important, tlough the most uncultivated, of human diseases. It is deplorable to observe, in the report of the committee, the treatment to which the unhappy sufferers are subjected-distracted in mind and tortured in body-chained down naked to beastly cribs, from Saturdays till Mondays, without being once removed, with no other sounds to greet the ear, than the incoherent and horrible yellings of their maniacal companions, - with no other view to meet the eye than the bare walls of a madman's den. Who can contemplate such a scene without feelings of horror! ls it to be expected that oures can be effected in such a frightful hole-cures, indecd! who are the attendants?-unprofessional idiots, if we have read the evidence correctly-porters, uneducated servants, any one who happens to be in the way. In a word, the patients are not classed, but placed together like a herd of swine. Taken altogether, it is a most infamous system, and casts a deep stain on the humane character of the influential people of this country. The public, however, are much indebted to Lord RoBERT SEYMOUR, Mr. ROBERT Brown, and Mr. GaRRETT Dillon, for having, by their indefatigable exertions, succeeded in procuring the appoint. ments of the parliamentary committee, which we can already perceive will be followed by very importan results.

We shall return to the subject, and give some extracts from the REPORT. 